\title{
Author's response to: letter to the editor
}

\author{
Anne Pernille Ofstad ${ }^{1,2} \cdot$ Dan Atar $^{3,4} \cdot$ Lars Gullestad $^{4,5} \cdot$ Gisle Langslet $^{6} \cdot$ Odd Erik Johansen $^{1,2}$
}

Published online: 24 July 2018

(C) Springer Science+Business Media, LLC, part of Springer Nature 2018

Thank you very much for the comment to our review article "The heart failure burden of type 2 diabetes mellitus - a review of pathophysiology and interventions." For patients with a treatment refractory heart failure, or difficult-to-treat heart failure, alternative etiologies should be sought. Herein, considerations of inflammation and autoimmunity are highly relevant. Addressing inflammation is relevant as there are suggestions of potential benefit of intravenous immunoglobulin therapy in patients with heart failure of different etiologies including dilated cardiomyopathy [1], and addressing autoimmunity is relevant since removal of cardiac autoantibodies could result in symptom relief. However, we would like to emphasize that although the method of immunoadsorption is well characterized for certain autoantibodies, the identification and characterization of the key contributing autoantibody/ies that promote cardiac damage leading to heart failure, and thus the identification of patients that are likely to benefit from treatment, is not yet established, nor is this method broadly established in clinical practice [2]. Immunoadsorption is therefore not recommended by the European Society of Cardiology's, or the American Heart Association and American College of Cardiology's guidelines [3-5], although recommended by the American Society of Apheresis as mentioned by the authors.

Anne Pernille Ofstad

Annepernille@hotmail.com

1 Bærum Hospital, Vestre Viken HF, Rud, Norway

2 Medical department, Boehringer Ingelheim, Asker, Norway

3 Department of Cardiology B, Oslo University Hospital, Ullevål hospital, Oslo, Norway

4 Faculty of Medicine, University of Oslo, Oslo, Norway

5 Department of cardiology, Oslo University Hospital, Rikshospitalet, Oslo, Norway

6 Lipid clinic, Oslo University Hospital, Rikshospitalet, Oslo, Norway
Thus, for the majority of patients with concomitant heart failure and type 2 diabetes, treatment with guideline recommended heart failure-specific therapy and careful selection of blood glucose lowering treatment remains key, whereas for those being treatment refractory, after having considered underlying causes such as poor drug compliance and secondary, acute illnesses, assessment of other causes is imperative, where immunomodulating therapy or immunoadsorption could be options for consideration.

\section{References}

1. Gullestad L, Aass H, Fjeld JG, Wikeby L, Andreassen AK, Ihlen H, Simonsen S, Kjekshus J, Nitter-Hauge S, Ueland T, Lien E, Froland SS, Aukrust P (2001) Immunomodulating therapy with intravenous immunoglobulin in patients with chronic heart failure. Circulation 103(2):220-225

2. Boivin-Jahns V, Jahns R, Boege F (2018) Relevant effects of beta1adrenoceptor autoantibodies in chronic heart failure. Front Biosci (Landmark Ed) 23:2146-2156

3. (2016) 2016 ESC Guidelines for the diagnosis and treatment of acute and chronic heart failure: The Task Force for the diagnosis and treatment of acute and chronic heart failure of the European Society of Cardiology (ESC). Developed with the special contribution of the Heart Failure Association (HFA) of the ESC. Eur J Heart Fail 18(8):891-975

4. Yancy CW, Jessup M, Bozkurt B, Butler J, Casey DE Jr, Colvin MM, Drazner MH, Filippatos GS, Fonarow GC, Givertz MM, Hollenberg SM, Lindenfeld JA, Masoudi FA, McBride PE, Peterson PN, Stevenson LW, Westlake C (2017) ACC/AHA/HFSA focused update of the $2013 \mathrm{ACCF} / \mathrm{AHA}$ guideline for the management of heart failure: a report of the American College of Cardiology/American Heart Association Task Force on Clinical Practice Guidelines and the Heart Failure Society of America. J Card Fail 23(8):628-651

5. Bozkurt B, Colvin M, Cook J, Cooper LT, Deswal A, Fonarow GC, Francis GS, Lenihan D, Lewis EF, McNamara D, Pahl E, Vasan RS, Ramasubbu K, Rasmusson K, Towbin JA, Yancy C, American Heart Association Committee on Heart Failure and Transplantation of the Council on Clinical Cardiology; Council on Cardiovascular Disease in the Young; Council on Cardiovascular and Stroke Nursing; Council on Epidemiology and Prevention; and Council on Quality of Care and Outcomes Research (2016) Current diagnostic and treatment strategies for specific dilated cardiomyopathies: a scientific statement from the American Heart Association. Circulation 134(23):e579-e646 